WEB COLOMBIAN MULTICENTER EXPERIENCE (WEB. COM): CLINICAL AND RADIOLOGICAL MID- LONG TERM RESULTS IN THE TREATMENT OF INTRACRANIAL ANEURYSMS USING INTRASACCULAR FLOW DISRUPTERS

'B Pabon*, 'M Patiño, ${ }^{1} \mathrm{O}$ Vargas, 'V Torres, '1 Gutierrez, ${ }^{2} \mathrm{~J}$ Fernandez, ${ }^{2} \mathrm{R}$ Alemeida, ${ }^{3} \mathrm{~F}$ Orozco, ${ }^{4} \mathrm{~N}$ Lobelo, ${ }^{5} \mathrm{M}$ Fonseca, ${ }^{6} \mathrm{~A}$ Pedroza, ${ }^{6} \mathrm{~W}$ Escobar. ${ }^{1}$ Neurointevencionismo, AngioTeam, Medellin, Colombia; ${ }^{2}$ Neurointevencionismo, Clínica Costa azul, Barranquilla, Colombia; ${ }^{3}$ Neurointevencionismo, Neurodinamia, Cartagena, Colombia; ${ }^{4}$ Neurointevencionismo, Clínica Colombia, Bogotá, Colombia; ${ }^{5}$ Neurointevencionismo, Neuroendovascular Surgery, Cúcuta, Colombia; ${ }^{6}$ Neurointevencionismo, Centro Medico Imbanaco, Cali, Colombia

\subsection{6/neurintsurg-2020-SNIS.253}

Introduction Woven EndoBridge (WEB) is a novel device for the treatment of ruptured and unruptured bifurcation aneurysms. To our knowledge none experience in Latin America has been reported. Here, we present a multi-center experience including mid and long-term follow data of patients treated with WEB.

Materials and Methods Consecutive patients treated with WEB were selected from March 2016 to February 2020 in six different centers in our country. We retrospectively evaluated clinical records, anatomical and angiographic variables. Additionally, WEB technical aspects, Procedure time and the presence of adverse events procedure-related were registered. Immediately angiographic results and mid, long term- follow up were analyzed and described below.

Results 73 patients (mean age: 52.8) with 75 IA were treated with WEB. History of SAH in 16/75(21\%). A total of 84 devices attempted and finally implanted 75 (1.1 device per aneurysm) of these, eight devices were exchanged due to sizing failures, one case of WEB miss-opening was discharged. 59/75 (78.6\%) were located in anterior circulation (MCA: 32, ACA: 19, ICA: 8). Sixteen cases in posterior circulation (Basilar tip: 13, SCA: 2, VBJ: 1). An additional strategy was observed in five cases (6.6\%): high porosity stent in four and balloon assisted web in one case. WEB SL was used in $82.6 \%$ and WEB SLS configuration in 13/75. Radiological follow up available 6-12 moths in 49/73 (67\%) with adequate occlusion rate according to WOS in $86.6 \%$. None thromboembolic complications. Two patients with severe hemorrhages procedurerelated (one case of ICA rupture due to DAC advancement, and one wire- perforation of tip- basilar aneurysm). Overall morbid-mortality of $2.6 \%$.

Conclusion In this multicenter experience the treatment of IA using WEB was feasible, safe and effective. Overall morbid-mortality $(2.6 \%)$ aligned with previous publications. Special care regarding sizing methodology and proper training to reach an accurate and fast learning curve should be considered. This technology constitutes a good and valuable tool to treat bifurcation IA's but also is on the way to be applied in different scenarios than WNBA in highly selected patients.

Disclosures B. Pabon: None. M. Patiño: None. O. Vargas: None. V. Torres: None. J. Gutierrez: None. J. Fernandez: None. R. Alemeida: None. F. Orozco: None. N. Lobelo: None. M. Fonseca: None. A. Pedroza: None. W. Escobar: None.

\section{E-223 CLINICAL AND ANGIOGRAPHIC RESULTS WITH THE NEW GENERATION SURPASS FLOW DIVERTER, EVOLVE: A SINGLE CENTER REAL WORLD EXPERIENCE}

S Derakhshani*, J Lynch, L Kanagarajah. Neuroradiology, Queen's University Hospital, Greater London, UK

\subsection{6/neurintsurg-2020-SNIS.254}

Objectiv To share the angiographic and clinical outcome in 35 consecutive patients treated with new generation Surpass Evolve Flow Diverter in our institution by a single operator team.

Methods Thirty-five consecutive patients (70\% women, average age 58 years), with anterior or posterior circulation aneurysms treated with Surpass Evolve FD in a single centre. Technical, clinical and angiographic results were analyzed.

Results Thirty-six Surpass Evolve were successfully implanted in all subjects to treat 35 patients using an XT 27 ( 0.027') microcatheter supported by a Cathayst 5, $0.58 \mathrm{~F}$ distal access system and a proximal $0.88 \mathrm{~F}$ long sheath. No deployment failure in our series was observed. No intraprocedural morbidity or mortality was seen. No increase in the mRS until March 2020. Clinical and angiographic follow-ups are ongoing and will be completed and presented at the annual meeting.

Conclusions Our preliminary experience demonstrates good performance of the Surpass Evolve with no intraprocedural mortality and morbidity and no increase in mRS until the time of submission of this paper. The follow-ups are still in process and full results will be presented at the meeting. The technology is a more user-friendly technology due to the device characteristics with far easier advancement, the accuracy of placement and adjustment features.

Disclosures S. Derakhshani: None. J. Lynch: None. L. Kanagarajah: None.

\section{E-224 COMPARING EFFICACY OF PLATELET INHIBITION IN PATIENT TREATED WITH CLOPIDOGREL VERSUS PRASUGREL UNDERGOING CEREBRAL ANEURYSM STENT-ASSISTED EMBOLIZATION WITH FLOW DIVERSION}

${ }^{1}$ E Milosavljevic* ${ }^{2}{ }^{2}$ McKinney, ${ }^{3}$ D Hoss. ${ }^{1}$ Radiology, Loma Linda University, Loma Linda University, CA; ${ }^{2}$ Radiology, Loma Linda University School of Medicine, Loma Linda University, $C A ;{ }^{3}$ Radiology, Loma Linda University, Loma Linda, CA

\subsection{6/neurintsurg-2020-SNIS.255}

Clopidogrel and Prasugrel are both platelet inhibitors that act on the P2Y12 adenosine diphosphate receptor. Clopidogrel utilizes a multi-step inhibition process while Prasugrel inhibits platelet functioning in a single step. In part due to these differences in mechanisms of action, an estimated $30 \%$ of patients treated with Clopidogrel are non-responders as compared to Prasugrel that has a very low rate of non-respondance. Inadequate platelet inhibition is associated with delay of care, often requiring operative rescheduling, and increased incidence of ischemic events. In our study, we compare a cohort of patients undergoing cerebral aneurysm embolization 